\title{
Predictive Mortality Factors after Decompressive Craniectomy in Ischemic Stroke
}

\section{Fatores preditivos de mortalidade após craniectomia descompressiva em acidentes vasculares cerebrais isquêmicos}

\author{
Maria Luísa Brito Almino Leite ${ }^{10}$ Matheus Silva Leite ${ }^{2(-)}$ Fernando Diogo Barbosa ${ }^{2(}$ \\ Iruena Moraes Kessler ${ }^{3}$
}

1 Universidade de Brasília, Brasília, DF, Brasil

Address for correspondence Maria Luísa Brito Almino Leite, MSc, SQS

2 Departament of Neurosurgery, Hospital de Base do Distrito Federal, 313 Bloco H, ap. 604, Asa Sul, Brazil Brasília, DF, Brasil

(e-mail: marialuisabfa@hotmail.com).

${ }^{3}$ Department of Neurosurgery, Universidade de Brasília, Brasília, DF, Brasil

Arq Bras Neurocir 2022;41(2):e95-e101.

\begin{abstract}
\section{Keywords}

- ischemic stroke

- cerebrovascular stroke

- middle cerebral artery

- decompressive craniectomy

Background Decompressive craniectomy is a consolidated method for the treatment of malignant ischemic stroke (iS) in the territory of the middle cerebral artery. Thus, factors contributing to mortality constitute an important area of investigation.

Objective To evaluate the epidemiological clinical profile and predictors of mortality in a single-center population of patients undergoing decompressive craniectomy for the treatment of malignant is.

Methods A single-center retrospective study was performed in 87 patients with malignant is subjected to emergency decompressive craniectomy from January 2014 to December 2017. Age, gender, laterality, aphasia, time interval between disease onset and treatment, and clinical and neurological outcomes using the Glasgow coma scale were assessed. The patients were stratified by age: a group of participants 60 years old or younger, and a group of participants older than 60 years old for assessment of survival and mortality by the Kaplan-Meier test and log-rank comparison. The intensity of the association between demographic and clinical variables was evaluated by multivariate Cox regression.

Results Ischemic stroke was prevalent in patients with hypertension (63.29\%). Seventyseven (84\%) patients had some type of postoperative complication, mostly pneumonia (42.8\%). The risk of death was $2.71(p=0.0041)$ and $1.93(p=0.0411)$ times higher in patients older than 60 and with less than 8 points on the Glasgow coma scale, respectively. Conclusion Malignant is has a significant mortality rate. Age above 60 years and Glasgow coma scale values below 8 were statistically correlated with unfavorable prognosis.
\end{abstract}

received

March 15, 2021

accepted

December 20, 2021

published online

February 25, 2022
DOI https://doi.org/ 10.1055/s-0042-1743106. ISSN 0103-5355. (c) 2022. Sociedade Brasileira de Neurocirurgia. All rights reserved. This is an open access article published by Thieme under the terms of the Creative Commons Attribution-NonDerivative-NonCommercial-License, permitting copying and reproduction so long as the original work is given appropriate credit. Contents may not be used for commercial purposes, or adapted, remixed, transformed or built upon. (https://creativecommons.org/ licenses/by-nc-nd/4.0/)

Thieme Revinter Publicações Ltda., Rua do Matoso 170, Rio de Janeiro, RJ, CEP 20270-135, Brazil 


\section{Resumo}

\section{Palavras-chave}

- acidente vascular cerebral isquêmico

- AVC maligno

- artéria cerebral média

- craniectomia descompressiva
Contexto A craniectomia descompressiva é um método consolidado para o tratamento do acidente vascular cerebral isquêmico (AVCI) maligno no território da artéria cerebral média. No entanto, os fatores envolvidos na mortalidade constituem objeto de investigação.

Objetivo Avaliar o perfil clínico epidemiológico e os preditores de mortalidade em uma população unicêntrica de pacientes submetidos à craniectomia descompressiva para tratamento de acidente vascular isquêmico maligno.

Métodos Um estudo retrospectivo unicêntrico foi realizado com 87 pacientes com AVCI maligno submetidos à craniectomia descompressiva de emergência de janeiro de 2014 a dezembro de 2017. Idade, gênero, lateralidade, afasia, intervalo de tempo entre o início da doença e o tratamento, e escala de coma de Glasgow foram avaliados. Os pacientes foram estratificados por idade: um grupo com participantes com 60 anos de idade ou menos, e outro com participantes com mais de 60 anos para avaliação de sobrevida e mortalidade pelo teste de Kaplan-Meier e comparação log-rank. A intensidade da associação entre variáveis demográficas e clínicas foi avaliada por regressão multivariada de Cox.

Resultados Houve prevalência de hipertensos (63,29\%). Setenta e sete (84\%) dos pacientes tiveram algum tipo de complicação pós-operatória, com predomínio de pneumonia (42,8\%). O risco de morte foi 2,71 e 1,93 maior em pacientes com mais de 60 anos e com menos de 8 pontos na escala de coma de Glasgow, respectivamente. Conclusão $\mathrm{O} \mathrm{AVCl}$ maligno ainda tem uma taxa de mortalidade significativa. Idade acima de 60 anos e valores da escala de coma de Glasgow abaixo de 8 foram estatisticamente correlacionados com um prognóstico desfavorável.

\section{Introduction}

\section{Malignant Stroke}

Ischemic stroke (iS), the most common and serious form of ischemic brain injury is a loss of neural function resulting from a critical reduction in cerebral blood flow. ${ }^{1}$ Up to $10 \%$ of iSs are associated with massive space-occupying swelling (e.g., malignant middle cerebral artery [MCA] infarct). Typically, these patients deteriorate over 48 to 96 hours, with a progressive decline in the level of consciousness, ultimately succumbing to cerebral herniation, often despite medical treatment. $^{2}$

The term "malignant hemispheric cerebral infarction" was introduced in 1996 and was described as a high morbidity and mortality clinical entity. It is an infarction that involves an area that covers at least two thirds of the MCA. ${ }^{3,4}$

The mortality of malignant infarction can be as high as $80 \%$ without neurosurgical intervention. ${ }^{4}$ Infarctions in MCA territory are clinically well described. ${ }^{5,6}$ The work of Foix and Levy, in the early 20th century, alludes to these infarctions. ${ }^{7,8}$

Currently, the description of malignant is is a cerebrovascular stroke affecting more than $50 \%$ of the MCA territory seen on computed tomography and/or cranial magnetic resonance imaging, consonant with clinical presentation. ${ }^{9-11}$

The rationale for decompressive surgery is to reduce intracranial pressure (ICP) and the vicious circle of extensive edema and further infarction. ${ }^{11}$ The best available evidence from recent randomized, controlled trials indicates that decompressive craniectomy is certainly a lifesaving operation in the setting of malignant stroke. ${ }^{12}$

The analysis of 3 published randomized studies (DECIMAL, ${ }^{13}$ DESTINY ${ }^{14}$ AND HAMLET $^{15}$ ) showed that the survival rate of the group subjected to decompressive surgery (78\%) more than doubled compared with that of the group treated conservatively (29\%). ${ }^{16,17}$ This staggering absolute risk reduction of $49 \%$ was highly significant. ${ }^{18}$

Despite the unquestionable efficacy of decompressive surgery, patient selection for this procedure is, to this date, a matter of discussion. Many studies were published trying to identify mortality predictors, helping the decision making about whom to operate. However, their results varied significantly. ${ }^{19-22}$

The present study took place in one of the many low- and middle-income countries where resources and scientific data are much scarcer. Highlighting this reality brings uniqueness to this article, making it meaningful in the literature.

\section{Materials and Methods}

This study involved a retrospective analysis of medical records of patients subjected to decompressive craniectomy for the treatment of malignant iS in a tertiary hospital in Distrito Federal, from January 2014 to December 2017. This research was approved by the research ethics committee of the Faculty of Medicine of Universidade de Brasília (CEP 
-FM/UNB), having been approved on the Brazil Platform under the CAAE registration protocol 13501018.7.0000.555.

The inclusion criteria were as follows: individuals older than 18 years of age were included in the study, and the following variables were considered: a) age, b) gender, C) time between ictus and decompressive craniectomy, D) laterality of the iS, E) presence of preoperative aphasia, F) postsurgical complications, G) comorbidities, H) Glasgow coma scale (GCS) score on admission, I) Glasgow coma scale score in the preoperative period, J) preoperative pupillary diameter and $\mathrm{L}$ ) prior chemical thrombolysis.

The exclusion criteria were as follows: A) patients younger than 18 years old, B) iS without involvement of the MCA, C) medical records with incomplete data, and D) traumatic is.

Multivariate Cox regression models were used, and hazard ratios with $95 \%$ confidence intervals were calculated to analyze the intensity of the association between demographic and clinical variables and mortality. In this model, after the initial crude analysis, the variables associated with mortality, that is, $p<0.25$, were included in the multivariate model. ${ }^{23}$

Kaplan-Meier estimators were used, and survival curves were constructed comparing age and postoperative complications (one group with pneumonia and other groups with pneumonia associated with other complications). Analyses were performed using the SAS 9.4 software (SAS Institute, Cary, NC, USA).

\section{Results}

The total sample had 87 patients, of whom 79 (90.8\%) of the medical records met the inclusion criteria. Eight (9.2\%) medical records were excluded ( 7 had incomplete data, and is was of traumatic origin in 1 case). Of the 79 cases, there was a predominance of females, which corresponded to $60.76 \%$ (48/79) of the sample, compared with $39.24 \%$ (31/79) males; the mean age was $50.48 \pm 11.75$ years old.

In the percentage distribution of patients per age, the sample was $40 \%$ (32/79) in the group under 50 years; $35.44 \%$ (28/79) between 50 and 59 years; $21.25 \%$ (17/79) between 60 and 69 years old; and 2.5\% (2/79) were between 70 and 79 years old.

Regarding laterality, $51.95 \%$ (41/79) were located in the left cerebral hemisphere, $46.75 \%$ (37/79) in the right cerebral hemisphere, and $1.3 \%(1 / 79)$ in both brain hemispheres. Of these, $49.37 \%$ (39/79) patients presented aphasia, and 8.86\% (7/79) patients presented with anisocoria on admission. As for the cerebral dominance of 39 aphasic patients, $77 \%$ of the patients had left dominance (30/39), while $23 \%$ of the patients (9/39) had right dominance.

Fifty patients (63.29\%) had hypertension, and 18 (22.78\%) patients had diabetes mellitus. A minimal number of patients underwent previous chemical thrombolysis for the treatment of malignant stroke $(9 / 79 ; 11.39 \%)$.

In the study, 39/77 patients (51\%) were admitted to intensive care units. There were two losses due to the discontinuation of evolution in the medical record without confirmation of intensive care unit (ICU) admission. The

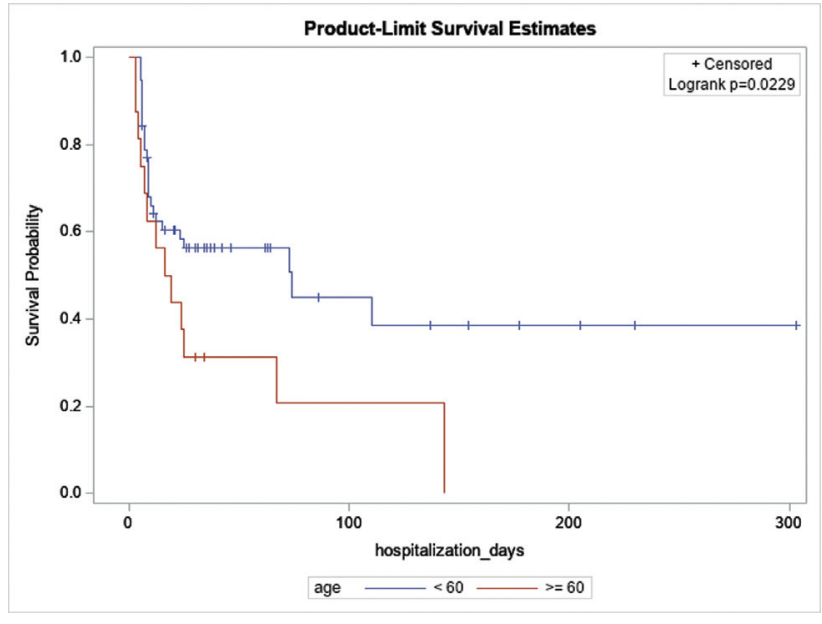

Fig. 1 Survival curve by age.

mortality rate was $55.84 \%$ ( 43 cases). The interval between ictus and surgery was $2.21 \pm 2.70$ days.

Of the patients who were admitted to the ICU, 26\% (10/39) were under 40 years old; $26 \%$ (10/39) were between 40 and 49 years old; $28 \%$ (11/39) were between 50 and 59 years old; and $20 \%$ of patients $(8 / 39)$ were over 60 years old;

Sixty-seven (84\%) patients experienced postoperative complications. Thirty-three patients (42.86\%) had pneumonia, and 19 (24.68\%) had sepsis. Fifteen patients had other complications (10 patients progressed to surgical wound infection, and 5 presented brain death).

Regarding the level of consciousness, a mean score of $12 \pm 3$ was observed on admission, and, at the time of surgery, the score was $10 \pm 3$ points on the GCS. Survival over 300 days was significantly lower in patients aged 60 years or older $(p=0.0229)$ ( $\boldsymbol{- F i g . 1}$ ); these patients had a risk of death 2.71 times higher than that of patients younger than 60 years old $(p=0.0041)$ ( $\sim$ Table 1 ).

The log-rank test results showed that the survival probability of patients who only had pneumonia as a postoperative complication did not differ significantly from the survival probability of those who had other types of complications during the follow-up period ( $p=0.9987$ ).

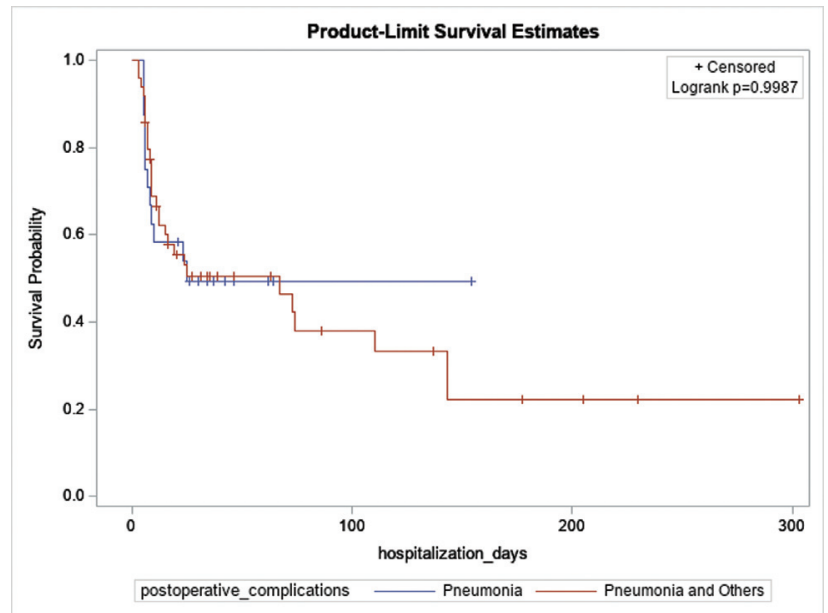

Fig. 2 Survival curve by postoperative complications. 
Table 1 Crude hazard ratio and adjusted hazard ratio for mortality by selected demographic and clinical variables $(N=73)$ - Cox regression

\begin{tabular}{|c|c|c|c|c|}
\hline & \multicolumn{4}{|c|}{ Hazard ratio - HR $(95 \% \mathrm{Cl})$} \\
\hline & Crude & $P$-value & Adjusted & $P$-value \\
\hline Age & & 0.0294 & & 0.0041 \\
\hline$<60$ & 1 & - & 1 & - \\
\hline$\geq 60$ & $2.05(1.07-3.92)$ & 0.0294 & $2.43(1.37-5.34)$ & 0.0041 \\
\hline Gender & & 0.1020 & - & - \\
\hline Female & 1 & - & - & - \\
\hline Male & $1.67(0.90-3.10)$ & 0.1020 & - & - \\
\hline From ictus to surgery & & 0.1172 & & 0.0526 \\
\hline$\leq 2$ & $1.93(0.85-4.41)$ & 0.1172 & $2.35(0.99-5.57)$ & 0.0526 \\
\hline$>2$ & 1 & - & 1 & - \\
\hline Glasgow at surgery & & 0.0995 & & 0.0411 \\
\hline$\leq 8$ & $1.68(0.91-3.11)$ & 0.0995 & $1.93(1.03-3.65)$ & 0.0411 \\
\hline$>8$ & 1 & - & 1 & - \\
\hline Alteplase & & 0.0022 & & 0.0012 \\
\hline No & 1 & - & 1 & - \\
\hline Yes & $3.83(1.62-9.07)$ & 0.0022 & $4.45(1.81-10.97)$ & 0.0012 \\
\hline Postoperative complication & & 0.9987 & & - \\
\hline Pneumonia & 1 & - & - & - \\
\hline Others complications & $1.00(0.50-1.98)$ & 0.9987 & - & - \\
\hline ICU admission & & 0.6406 & - & - \\
\hline No & $1.16(0.63-2.14)$ & 0.6406 & - & - \\
\hline Yes & 1 & - & - & - \\
\hline Systemic arterial hypertension & & 0.6668 & - & - \\
\hline No & 1 & - & - & - \\
\hline Yes & $1.16(0.60-2.24)$ & 0.6668 & - & - \\
\hline Diabetes mellitus & & 0.2455 & - & - \\
\hline No & 1 & - & - & - \\
\hline Yes & $1.47(0.77-2.82)$ & 0.2455 & - & - \\
\hline
\end{tabular}

Abbreviations: $\mathrm{Cl}$, confidence interval; ICU, intensive care unit.

A - age-adjusted, adjusted ictus until surgery, Glasgow at surgery and alteplase.

The use of alteplase showed a risk of death 4.45 times higher than when it was not used ( $p=0.0012)$, and GCS score $\leq 8$ was associated with a risk of death 1.93 times higher than when the GCS score was $>8(p=0.0411)$ ( $~-$ Table 1$)$. Patients older than 60 years of age had a risk of death 2.71 times higher than that of patients younger than 60 years old $(p=0.0042)$. In turn, patients with ictus $\leq 2$ presented a risk of death 2.35 times greater than that of patients with ictus $>2$, but this increase was not statistically significant $(p=0.0526)$.

\section{Discussion}

The present study evaluated the clinical-epidemiological variables associated with morbidity and mortality in patients undergoing decompressive craniectomy. These variables were age, gender, hypertension, diabetes, time from ictus to surgery, GCS score at surgery, previous infusion of alteplase, postoperative complications, and hospitalization or not in the ICU.

Vahedi, in a meta-analysis conducted in 2007, reported that patients who underwent surgery within 48 hours from ictus benefited from surgery and that the same benefit could not be proven after this period. The study also showed there was no additional benefit for the group operated on within 24 hours compared with the group operated on within 48 hours. $^{16}$ In our study, patients who underwent surgery within 48 hours after the event had a 2.35-fold higher mortality rate than those who underwent surgery after 48 hours of the the event; this result was not statistically significant $(p=0.0526)$. Most likely, those who underwent surgery within 48 hours after the event were considered more severe cases in the present study. 
Regarding the mortality related to patient gender, our study showed a hazard ratio of 1.67 for males; however, $p=0.10$, and the result was considered not significant. This result is consistent with a study of Campos et al (2011), in which they stated that gender does not have statistically significant predictive value to determine the course of cerebral stroke. ${ }^{24}$

There are reports in the literature indicating that clinical deterioration, evaluated by the decrease in GCS score from admission to surgery, ${ }^{25}$ and age are relevant factors for worse outcomes. $^{26}$

Koh et al. showed that outcomes were better when clinical deterioration of the preoperative GCS score remained at 9 or higher (66\% favorable, 33\% unfavorable) compared with when the GCS deteriorated to 8 or less ( $28 \%$ favorable, $72 \%$ unfavorable). The outcome was based on the Glasgow outcome score (GOS); a favorable outcome was a GOS between 4 and 5 (moderate or mild disability), and poor outcome was a GOS between 1 and 3 (death, vegetative state, or severe disability). ${ }^{27}$

Kilincer et al. showed that a presurgical GCS score lower than 8 is an important determinant of an unfavorable outcome, and that modified rank between 0 and 3 was associated with favorable outcomes, and modified rank between 4 and 6 was associated with unfavorable outcomes. ${ }^{28}$

In our study, patients with GCS scores equal to or lower than 8 had a risk of death 1.93 times higher than that of patients with GCS scores above $8(p=0.0411)$. These data have been important for not delaying the surgical approach until neurological deterioration occurs. No functional evaluation of the patients was performed; only a mortality variable was considered as a poor outcome.

In the present study, patients 60 years old or older presented a risk of death 2.71 times higher than that of patients younger than 60 years old $(p=0.0041)$. According to the log-rank test, the survival probability of patients 60 years old or older over the follow-up period of 300 days was significantly lower $(p=0.0229)$, which is in line with results reported by Arac et al. in 2009. In the review by Arac et al., the mortality rate was significantly higher in the group older than 60 years old ( 37 of 72 patients, 51.3\%) than in the group 60 years old or younger (41 of 197 patients, 20.8\%) $(p<0.0001) .^{29}$

This fact can be explained by the following factors: advanced age, that is, patients older than 50 years old, may have an effect on the brain's ability to compensate for the effects of a stroke; however, these individuals tend to have additional comorbidities that increase the risk of poor prognosis and death. In turn, young patients can expect better outcomes and receive aggressive care, and they are more resilient to medical comorbidities that directly affect longterm outcomes. ${ }^{30}$ However, the lack of atrophy may cause intolerance to extensive edema. ${ }^{26,31,32}$

Age is the most important risk factor for the development of a stroke. While the risk of stroke in the general population is $\sim 0.25 \%$ per year, this number doubles every decade for individuals older than 50 years old. At the age of 85 years old, the stroke incidence rate reaches $3.5 \% /$ year. ${ }^{33}$ Regardless of other factors, age is an independent predictor of poor outcomes. The upper age limit for performing decompressive craniectomy has also been discussed considering the riskbenefit of the procedure. ${ }^{26}$

In a prospective, randomized, controlled study, Zhao et al. compared patients with malignant iS aged 18 to 80 years old who underwent decompressive craniectomy with those in the same age group who did not. Their results showed that there was benefit of undergoing craniectomy within 48 hours, even for patients in more advanced age groups. ${ }^{34}$ However, approximately two thirds (18/29) of patients older than 60 years old were between 61 and 70 years old. Only 11 patients (4 randomized for surgery) were in the oldest subcohort, whose ages ranged between 71 and 80 years old. Although there are several studies indicating less beneficial effects for elderly patients, there has been a paucity of controlled prospective randomized studies. ${ }^{35}$

Eighteen patients (22.78\%) had diabetes mellitus, and 50 (63.29\%) had systemic arterial hypertension (SAH). These data are important because systolic and diastolic pressure levels are exponentially associated with the development of cerebrovascular disease. ${ }^{36}$ However, the results of the multivariate analysis were not statistically significant in relation to the mortality of patients with hypertension and diabetes.

Providing life-saving treatment for major infarcts in the dominant hemisphere is a controversial topic in the literature. The main concern has been that heroic interventions can leave patients with an unacceptably low quality of life because of aphasia. ${ }^{26}$ Data from the literature review, Gupta el al., however, do not restrict the surgical approach to the nondominant hemisphere. The functional outcomes among the 27 patients who underwent decompression of the dominant hemisphere was no worse than among the 111 patients who underwent decompression on the nondominant side. ${ }^{26}$

Among patients who suffer stroke, aphasia is the most prevalent language disorder among the total number of patients treated in the hospital environment. ${ }^{37}$ The frequency of aphasia among patients who have suffered stroke is 21 to $38 \%{ }^{38}$ There was a high prevalence of patients with aphasia in the present study, that is, 40 patients, corresponding to $50.63 \%$ of the patients, which is the largest result found in the literature.

Patients who used alteplase exhibited a 4.45 times higher risk of death than those who did not use the thrombolytic agent $(p=0.0012)$. The risk of death was related to increased bleeding and surgical morbidity. Nine patients underwent thrombolysis prior to surgery, corresponding to $11.39 \%$ of the total population studied. This percentage of patients with thrombolysis was probably higher than expected, given that extensive iSs are contraindicated for venous thrombolysis. This can be explained by the unavailability of magnetic resonance imaging (MRI) in the emergency department, which is a more sensitive imaging test for the early diagnosis of is than computed tomography. ${ }^{39}$ It is not possible to determine from this study or from the existing literature whether the increase in mortality caused by the previous use of alteplase would lead this group of patients to be ineligible for decompressive craniectomy. 


\section{Conclusion}

Decompressive craniectomy for the treatment of malignant iS is a consolidated and effective surgical intervention; however, this clinical entity still has a significant mortality rate, despite this procedure increasing patient survival.

Age can be a tool to help guide surgical decisions because elderly patients have a significantly higher mortality rate. However, the treatment must be individualized, as a GCS score lower than 8 is also associated with higher mortality. Age over 60 years and GCS values below 8 were statistically correlated with an unfavorable prognosis.

\section{Conflict of Interests}

The authors have no conflict of interests to declare.

\section{References}

1 Kahle KT, Simard JM, Staley KJ, Nahed BV, Jones PS, Sun D. Molecular mechanisms of ischemic cerebral edema: role of electroneutral ion transport. Physiology (Bethesda) 2009; 24:257-265

2 Harbaugh R, Shaffrey CI, Couldwell WT, Berger MS. Neurosurgery Knowledge Update: A Comprehensive Review. 1st edition New York: Stuttgart, Dehli; 2015

3 Krieger DW, Demchuk AM, Kasner SE, Jauss M, Hantson L. Early clinical and radiological predictors of fatal brain swelling in ischemic stroke. Stroke 1999;30(02):287-292

4 Hacke W, Schwab S, Horn M, Spranger M, De Georgia M, von Kummer R. 'Malignant' middle cerebral artery territory infarction: clinical course and prognostic signs. Arch Neurol 1996;53 (04):309-315

5 Kase CS. Middle cerebral artery syndromes. In: Vinken PJ, Bruyn GW, Klawans HL, Toole JF, editors.Vascular diseases Part 1 (v. 53 , revised series 9) Handbook of clinical neurology. Amsterdam: Elsevier Science; 1988:1-20

6 Mohr JP, Gautier J, Hier DB. Middle cerebral artery disease. In: Barnett JM, Mohr JP, Stein BM, Frank M, editors. Stroke: pathophysiology, diagnosis, and management. v 1., 2. ed. Nova York: Churchill Livingstone; 1992

7 Foix C, Levy MLes ramollissements sylviens. Syndromes des lesions en foyer du territoire de l'artere sylvienne et de ses branches. Rev Neurol (Paris) 1927;2(01):1-51

8 Donnan GA, Levi CR. Large and panhemispheric infarcts. In: Bogousslavsky J, Caplan LR, editors. Stroke syndromes. New York: Cambridge University Press; 1995

9 Mori K, Aoki A, Yamamoto T, Horinaka N, Maeda M. Aggressive decompressive surgery in patients with massive hemispheric embolic cerebral infarction associated with severe brain swelling. Acta Neurochir (Wien) 2001;143(05):483-491, discussion 491-492

10 Steiner T, Ringleb P, Hacke W. Treatment options for large hemispheric stroke. Neurology 2001;57(5, Suppl 2):S61-S68

11 Yao Y, Liu W, Yang X, Hu W, Li G. Is decompressive craniectomy for malignant middle cerebral artery territory infarction of any benefit for elderly patients? Surg Neurol 2005;64(02):165-169, discussion 169

12 Harbaugh RE, Shaffrey C, Couldwell WT, et al. Neurosurgery Knowledge Update. 1st ed. Thieme E-Books; 2015

13 Vahedi K, Vicaut E, Mateo J, et al; DECIMAL Investigators. Sequential-design, multicenter, randomized, controlled trial of early decompressive craniectomy in malignant middle cerebral artery infarction (DECIMAL Trial). Stroke 2007;38(09):2506-2517

14 Jüttler E, Schwab S, Schmiedek P, et al; DESTINY Study Group. Decompressive Surgery for the Treatment of Malignant Infarction of the Middle Cerebral Artery (DESTINY): a randomized, controlled trial. Stroke 2007;38(09):2518-2525

15 Hofmeijer J, Amelink GJ, Algra A, et al; HAMLET investigators. Hemicraniectomy after middle cerebral artery infarction with life-threatening Edema trial (HAMLET). Protocol for a randomised controlled trial of decompressive surgery in space-occupying hemispheric infarction. Trials 2006;7:29

16 Vahedi K, Hofmeijer J, Juettler E, et al; DECIMAL, DESTINY, and HAMLET investigators. Early decompressive surgery in malignant infarction of the middle cerebral artery: a pooled analysis of three randomised controlled trials. Lancet Neurol 2007;6(03):215-222

17 Rincon F, Mayer SA. Decompressive surgery in malignant infarction of the middle cerebral artery. Curr Neurol Neurosci Rep 2007; 7(06):511-512

18 Mayer SA. Hemicraniectomy: a second chance on life for patients with space-occupying MCA infarction. Stroke 2007;38(09): 2410-2412

19 Kamran S, Salam A, Akhtar N, et al. Predictors of In-Hospital Mortality after Decompressive Hemicraniectomy for Malignant Ischemic Stroke. J Stroke Cerebrovasc Dis 2017;26(09): 1941-1947

20 Maramattom BV, Bahn MM, Wijdicks EFM. Which patient fares worse after early deterioration due to swelling from hemispheric stroke? Neurology 2004;63(11):2142-2145

21 Kasner SE, Demchuk AM, Berrouschot J, et al. Predictors of fatal brain edema in massive hemispheric ischemic stroke. Stroke 2001;32(09):2117-2123

22 Walz B, Zimmermann C, Böttger S, Haberl RL. Prognosis of patients after hemicraniectomy in malignant middle cerebral artery infarction. J Neurol 2002;249(09):1183-1190

23 Hosmer DW, Lemeshow S. Applied logistic regression. 2nd ed. New York: John Wiley \& Sons; 2000

24 Campos WK, Guasti JAD. Infarto cerebral hemisférico: algoritmo de tratamento baseado em evidência. Braz Neurosurg 2011;30 (02):76-83

25 Mattos JP, Joaquim AF, Almeida JP, et al. Decompressive craniectomy in massive cerebral infarction. Arq Neuropsiquiatr 2010;68 (03):339-345

26 Gupta R, Connolly ES, Mayer S, Elkind MSV. Hemicraniectomy for massive middle cerebral artery territory infarction: a systematic review. Stroke 2004;35(02):539-543

27 Koh MS, Goh KY, Tung MY, Chan C. Is decompressive craniectomy for acute cerebral infarction of any benefit? Surg Neurol 2000;53 (03):225-230

28 Kilincer C, Asil T, Utku U, et al. Factors affecting the outcome of decompressive craniectomy for large hemispheric infarctions: a prospective cohort study. Acta Neurochir (Wien) 2005;147(06): 587-594, discussion 594

29 Arac A, Blanchard V, Lee M, Steinberg GK. Assessment of outcome following decompressive craniectomy for malignant middle cerebral artery infarction in patients older than 60 years of age. Neurosurg Focus 2009;26(06):E3

30 Sheth KN. Management of Hemispheric Infarction and Ischemic Swelling. Continuum (Minneap Minn) 2015;21(5 Neurocritical Care):1346-1361

31 Nobre MC, Monteiro M, Albuquerque AC, et al. Craniectomia descompressiva para tratamento de hipertensão intracraniana secundária a infarto encefálico isquêmico extenso: análise de 34 casos. Arq Neuropsiquiatr 2007;65(01):107-113

32 Holtkamp M, Buchheim K, Unterberg A, et al. Hemicraniectomy in elderly patients with space occupying media infarction: improved survival but poor functional outcome. J Neurol Neurosurg Psychiatry $2001 ; 70(02): 226-228$

33 Kugler C, Altenhöner T, Lochner P, Ferbert AHessian Stroke Data Bank Study Group ASH. Does age influence early recovery from ischemic stroke? A study from the Hessian Stroke Data Bank. J Neurol 2003;250(06):676-681 
34 Zhao J, Su YY, Zhang Y, et al. Decompressive hemicraniectomy in malignant middle cerebral artery infarct: a randomized controlled trial enrolling patients up to 80 years old. Neurocrit Care 2012;17(02):161-171

35 Zweckberger K, Juettler E, Bösel J, Unterberg WA. Surgical aspects of decompression craniectomy in malignant stroke: review. review Cerebrovasc Dis 2014;38(05):313-323

36 MacMahon S, Rodgers A. Primary and secondary prevention of stroke. Clin Exp Hypertens 1996;18(3-4):537-546
37 Ortiz KZ, Marinelli MR. Investigação da Queixa de Disfagia em Pacientes Afásicos. Rev CEFAC 2013;15:1503-1511

38 Pedersen PM, Jørgensen HS, Nakayama H, Raaschou HO, Olsen TS. Aphasia in acute stroke: incidence, determinants, and recovery. Ann Neurol 1995;38(04):659-666

39 Senra D. Medicina Intensiva: Fundamentos e Prática. São Paulo: $1^{\text {a }}$ edição Atheneu, 2013. 